\title{
Postpartum hemorrhage control by double-balloon catheters.
}

\author{
Oroma Beatrice Nwanodi* \\ Obstetrics and Gynecology Locum Tenens, Banner Health, Sutter Health, USA
}

Accepted on January 27, 2018

\section{Commentary}

The overarching goal of PPH control is to prevent maternal mortality [1]. In Africa and Asia, PPH accounts for 30\% of pregnancy-associated mortality [2]. The incidence of $\mathrm{PPH}$ in cases of placenta previa is $22.3 \%$ (95\% CI $15.8-28.7 \%$ ) [2]. North America has the highest rate of placenta previa associated $\mathrm{PPH}$ at $26.3 \%$, Asia is mid-range at $20.7 \%$, and Europe the lowest at $17.8 \%$ [2]. Globally, placenta previa has a prevalence of 5.2 per 1,000 pregnancies $(95 \%$ Confidence Interval [CI]: 4.5-5.9) [3]. Placenta previa is most prevalent in Asia at 12.2 per 1,000 pregnancies (95\% CI: 9.5-15.2) [3]. Thus, even though Asia does not have the highest placenta previa associated $\mathrm{PPH}$ rate, given the $30 \%$ PPH pregnancy-associated mortality, PPH control is reasonably the focus of studies in Asia [4]. The literature on double-balloon tamponade for PPH in cases of placenta previa reports $88 \%$ to $100 \%$ success, confirmed by a recent retrospective case series with 112 women that achieved a $97.4 \%$ success rate [4]. Mean blood loss was $1983 \pm 512.2$ $\mathrm{mL}$. There were no postpartum infections. However, as post discharge follow-up is not given, it is unknown if any of these patients subsequently had uneventful pregnancies [4].

The risk of peripartum hysterectomy for abnormal placentation, excluding uterine atony, is 0.11 to 6.38 per 1,000 deliveries [5]. Direct costs of peripartum hysterectomy were $£ 5,380$ (95\% CI $£ 4,436-£ 6,687)$ in 2015 prices [6]. Six-month Short Form 36 quality of life scoring indicates that patients who experienced peripartum hysterectomy for placenta accreta spectrum experience more pain that women who undergo complicated cesarean deliveries, $p=0.013$ [7]. Post-procedure surveillance questionnaire responses indicated increased re-hospitalization $(\mathrm{p}=0.045)$, more dyspareunia $(\mathrm{p}=0.025)$, and more anxiety and worry $(\mathrm{p}=0.027)$ in peripartum hysterectomy patients than in patients who had complicated cesarean deliveries [7]. These subsequent adverse effects to the patient and her family should be avoided. Therefore, increased double-balloon catheter use to control PPH and preclude peripartum hysterectomy is important to mothers and their families. The reported retrospective case series and literature quoted therein have high success rates for double-balloon catheter control of placentation-caused PPH [4]. Other studies give $50 \%$ complete to $88 \%$ partial success rates [1]. Estimated blood loss is comparable, mean $2,375 \mathrm{~mL}$ [1]. However, balloon fill volumes vary, with mean uterine balloon inflation with $675 \mathrm{~mL}(400 \mathrm{~mL}-800 \mathrm{~mL})$ and vaginal balloon $263 \mathrm{~mL}(150 \mathrm{~mL}-300 \mathrm{~mL})$ [2]. Use of double-balloon catheters as second-line intervention for PPH is recommended to reduce the amount of procedures performed for PPH control [1]. Benefits of double-balloon catheters include those of stopping $\mathrm{PPH}$, and method-specific benefits. The benefits of stopping $\mathrm{PPH}$ are prevention of additional interventions including peripartum hysterectomy, reducing maternal hospitalization length of stay, and reducing maternal anemia. Double-balloon catheters have a method-specific benefit over single-balloon catheters as the vaginal balloon obviates the need for vaginal packing and can reduce retained foreign body incidence [1]. As double-balloon catheters become increasingly used for second-and third trimester labor inductions and management of bleeding following ectopic pregnancy treatment, familiarity may increase double-balloon catheter use as second line gynecologic and obstetric uterine bleeding control.

\section{References}

1. Dildy GA, Belfort MA, Adair CD, et al. Initial experience with a dual-balloon catheter for the management of postpartum hemorrhage. Am J Obstet Gynecol 2014;210:136.e1-136.e6.

2. Fan D, Xia Q, Liu L, et al. The incidence of postpartum hemorrhage in pregnant women with placenta previa: A systematic review and meta-analysis. PLOS ONE 2017;12: e0170194.

3. Cresswell JA, Ronsmans C, Calvert C, et al. Prevalence of placenta previa by world region: A systematic review and meta-analysis. Trop Med and Int Health. 2013;18:712-724.

4. Duan Y, Zhao J, Kang S, et al. Double-balloon tamponade used to control postpartum hemorrhage due to placenta previa and/or placenta accreta. Gynecol Reproduct Endocrinol 2017;1:21-23.

5. Machado LSM. Emergency peripartum hysterectomy: Incidence, indications, risk factors and outcome. $\mathrm{N} \mathrm{Am} \mathrm{J}$ Med Sci 2011;3:358-361.

6. Achana FA, Fleming KM, Tata LJ, et al. Peripartum hysterectomy: An economic analysis of direct healthcare costs using routinely collected data. BJOG 2017.

7. Keenan K, Einerson BD, Gibbons KJ, et al. Patient-reported health outcomes and quality of life after peripartum hysterectomy for placenta accrete spectrum (PAS). Am J Obstet Gynecol 2018;218:S579-S580.

\section{*Correspondence to:}

Oroma Beatrice Nwanodi

Obstetrics and Gynecology Locum Tenens

Banner Health, Sutter Health

USA

Tel: (314) 304-2946

E-mail: o.nwanodi@juno.com 